\title{
Endobronchial Ultrasound-Guided Transbronchial Needle Aspiration (EBUS-TBNA): Technical Updates and Pathological Yield
}

\author{
Huzaifa A. Jaliawala ${ }^{1}$, Samid M. Farooqui ${ }^{1}$ (D), Kassem Harris ${ }^{2}$, Tony Abdo ${ }^{1}$, Jean I. Keddissi ${ }^{1}$ \\ and Houssein A. Youness $1, * \mathbb{D}$ \\ 1 Interventional Pulmonary Program, Section of Pulmonary, Critical Care and Sleep Medicine, The Oklahoma \\ City VA Health Care System, The University of Oklahoma Health Sciences Center, Oklahoma City, OK 73104, \\ USA; Huzaifa-Jaliawala@ouhsc.edu (H.A.J.); Samid-Farooqui@ouhsc.edu (S.M.F.); \\ Tony-Abdo@ouhsc.edu (T.A.); jean-keddissi@ouhsc.edu (J.I.K.) \\ 2 Division of Pulmonary and Critical Care Medicine, Section of Interventional Pulmonology, Westchester \\ Medical Center, Valhalla, NY 10595, USA; Kassem.Harris@wmchealth.org \\ * Correspondence: Houssein-Youness@ouhsc.edu; Tel.: +1-405-271-6173
}

Citation: Jaliawala, H.A.;

Farooqui, S.M.; Harris, K.; Abdo, T.;

Keddissi, J.I.; Youness, H.A.

Endobronchial Ultrasound-Guided

Transbronchial Needle Aspiration (EBUS-TBNA): Technical Updates and Pathological Yield. Diagnostics 2021, 11, 2331. https://doi.org/

10.3390/diagnostics11122331

Academic Editor: Byeong-Ho Jeong

Received: 29 September 2021

Accepted: 6 December 2021

Published: 10 December 2021

Publisher's Note: MDPI stays neutral with regard to jurisdictional claims in published maps and institutional affiliations.

\begin{abstract}
Since the endobronchial ultrasound bronchoscope was introduced to clinical practice, endobronchial ultrasound-guided transbronchial needle aspiration (EBUS-TBNA) has become the procedure of choice to sample hilar and mediastinal adenopathy. Multiple studies have been conducted in the last two decades to look at the different technical aspects of the procedure and their effects on the final cytopathological yield. In addition, newer modes of ultrasound scanning and newer tools with the potential to optimize the selection and sampling of the target lymph node have been introduced. These have the potential to reduce the number of passes, reduce the procedure time, and increase the diagnostic yield, especially in rare tumors and benign diseases. Herein, we review the latest updates related to the technical aspects of EBUS-TBNA and their effects on the final cytopathological yield in malignant and benign diseases.
\end{abstract}

Keywords: endobronchial ultrasound; transbronchial needle aspiration; diagnostic yield

\section{Introduction}

Over the last two decades, there have been major developments in our ability to sample mediastinal and peribronchial structures. We have come a long way from the initial use of transbronchial needle aspiration (TBNA) for sampling through a rigid bronchoscope in 1949, to Wang et al. introducing TBNA through flexible bronchoscopy in 1983. Endobronchial ultrasound (EBUS) with real-time visualization of mediastinal structures was first employed in 1992 [1]. As pulmonologists gain more experience in performing EBUS-TBNA, the ability to diagnose pathological involvement of mediastinal structures has significantly improved. The American College of Chest Physicians (ACCP) guidelines for non-small cell lung cancer (NSCLC) report that EBUS-TBNA has a 91\% sensitivity in establishing a diagnosis as compared with $81 \%$ for cervical mediastinoscopy [2]. Given EBUS-TBNA's minimally invasive nature and high sensitivity, it has become the procedure of choice to stage the mediastinum [3].

Multiple studies have evaluated different components of the EBUS-TBNA procedure to optimize the pathological yield and eliminate unnecessary steps while reducing the time and complications. Newer ultrasound modes and many bronchoscopic tools have been introduced to optimize the selection of the lymph node and the collection of cytological and histological material.

In this article, we aim to review the latest updates related to the technical performance of EBUS-TBNA and describe how emergent data can affect its diagnostic yield in lung 
cancer. In addition, we discuss the utility of EBUS-TBNA in the diagnosis of lymphoma and sarcoidosis.

\section{Procedure-Related Technical Factors and Their Effects on Diagnostic Yield}

\subsection{Choice of Sedation}

EBUS-TBNA is usually performed in the endoscopy suite under moderate sedation (MS), deep sedation, or general anesthesia (GA) [4]. The choice of anesthesia strategy is largely driven by institutional policy and operator preference. In a prospective randomized study, Casal et al. compared the diagnostic yield of EBUS-TBNA performed under MS with GA. There was no difference in the diagnostic yield, the number of lymph nodes (LN) sampled, the number of passes per LN, or the rate of major complications. It should be noted that $6 \%$ of patients assigned to the MS group did not tolerate sedation, and the EBUS-TBNA had to be done under GA [5].

\subsection{Needle Size}

The optimal needle size has been a subject of interest for interventional pulmonologists since the introduction of EBUS-TBNA. The factors that need to be considered are the ability to acquire satisfactory specimens to establish the diagnosis without increasing the side effects. The current literature supports the use of $21 \mathrm{G}$ or $22 \mathrm{G}$ needles, as no difference in specimen adequacy or diagnostic yield was found between the two sizes [6].

When compared with the $22 \mathrm{G}$ needle in sampling the same LN, the $25 \mathrm{G}$ needle had a similar diagnostic yield for malignancy. The histology specimens containing malignant cells and the number of malignant cells were significantly higher in the $22 \mathrm{G}$ compared with the $25 \mathrm{G}$ needle, and no difference in complications was seen $[7,8]$. Other studies comparing aspirate done with $25 \mathrm{G}$ and $22 \mathrm{G}$ needles showed comparable specimen adequacy and diagnostic accuracy [9]. Similarly, there was no difference in specimen adequacy and diagnostic yield when the $25 \mathrm{G}$ needle was compared with the $21 \mathrm{G}$ needle [10].

Moreover, when the $22 \mathrm{G}$ was compared with the larger $19 \mathrm{G}$ needle in sampling the same LN in an alternating manner, there was no improvement in the overall diagnostic yield. However, more bloody passes and lower sample adequacy were observed with the $19 \mathrm{G}$ needle aspirates [11]. Similarly, in a randomized controlled trial of 78 patients, Dooms et al. showed that despite having a larger tissue aspirate, the specimen was bloodier with the $19 \mathrm{G}$ needle, with an overall similar diagnostic yield and specimen quality compared with the $22 \mathrm{G}$ needle [12].

In a prospective analysis of 83 EBUS-TBNA samples obtained from 47 patients, sampling of the same LN with $19 \mathrm{G}$ and $21 \mathrm{G}$ needles showed more cellular material based on the cell area in the cell block obtained with the $19 \mathrm{G}$ compared with the $21 \mathrm{G}$ (7.34 vs. $5.23 \mathrm{~mm}^{2}, p=0.02$ ) [13]. In a prospective randomized controlled trial that included 107 patients, Wolters et al. showed that aspirates using the $19 \mathrm{G}$ needle contained significantly more tissue and tumor cells compared with the $22 \mathrm{G}$ needle [14]. However, it remains unclear whether this difference affects the molecular analyses and PD-L1 staining of these specimens.

Conversely, in a retrospective single-center study, Jones et al. found a higher proportion of lymphoma $(9 \%, 5 \%$, and $0 \%$ ) and benign disease $(89 \%, 70 \%$, and $38 \%$ ) in $\mathrm{LN}$ sampled with the $19 \mathrm{G}, 21 \mathrm{G}$, and $22 \mathrm{G}$, respectively. The $19 \mathrm{G}$ needle was observed to be superior to both $21 \mathrm{G}$ and $22 \mathrm{G}$ in subclassifying malignant diseases, with lower rates of NSCLC-NOS (non-small cell lung cancer-not otherwise specified), and it reduced the need for invasive mediastinoscopy [15].

Although studies comparing different needle sizes did not show any statistically significant differences in diagnostic yield, we cannot exclude that a small difference may exist, especially as some of these studies were underpowered to detect a difference, had a retrospective design, and may not have tested different needles on the same lymph nodes (Table 1). 


\subsection{Use of Suction and Stylet}

EBUS-TBNA has traditionally been performed with the needle advanced and with a stylet occluding the needle until the lymph node is accessed under EBUS guidance. A $20 \mathrm{~cm}$ suction is then applied, and aspiration is done by moving the needle in the lymph node 10 to 20 times. The addition of suction has not been shown to improve the diagnostic yield or sample adequacy when compared with lower suction of $10 \mathrm{~cm}$ or no suction at all [16-18].

In a randomized controlled trial, Lin et al. evaluated the diagnostic yield of malignancy and the specimen adequacy of using suction and a stylet, suction with no stylet, and stylet with no suction. Each LN was sampled with the three methods using a $22 \mathrm{G}$ needle. There were no significant differences among the groups in specimen adequacy rate or diagnostic yield of malignancy, although using suction increased the tissue-core acquisition rate compared with the no suction group [19].

\subsection{Fanning}

Fanning is a technique employed by endoscopists to influence the diagnostic yield of a procedure. It consists of sampling multiple areas within a lymph node in each pass by altering the angle of the needle with each subsequent agitation during a pass. This was shown to be superior in EUS-FNA of pancreatic lesions [20], but no such data are present for EBUS-TBNA. However, preliminary data involving lymph nodes in ex vivo calf lungs have shown that fanning methods collected larger samples as compared with no fanning [21].

\subsection{Core Needle}

Core biopsy specimens can also be obtained via EBUS. These samples involve the use of a Franseen tip $22 \mathrm{G}$ fine needle biopsy (FNB) device equipped with three cutting edges (Acquire ${ }^{\circledR} 22$ G FNB needle, Boston Scientific Co., Natick, MA, USA) (Figure 1A-C). In a study evaluating the diagnostic yield of FNB in EUS compared with a historical control using the Expect ${ }^{\circledR} 22$ G FNA needle (Boston Scientific Co., Natick, MA, USA), FNB had better histological samples in fewer attempts [22]. In a retrospective analysis of the first 100 patients undergoing EBUS with FNB, Balwan et al. showed that core biopsy was seen in $87 \%$ of patients, the pathological diagnosis was established in $97 \%$, and the diagnostic yield for granulomatous lymphadenopathy was obtained in $95.6 \%$. No patient-related adverse events were noted [23].

The ProCore ${ }^{\circledR}$ needle from Cook Medical (Bloomington, IN, USA) is designed to provide a core of histological tissue in contrast to the cytological specimens from standard fine needle aspirations. It comes in two sizes, $22 \mathrm{G}$ and $25 \mathrm{G}$. It has a reverse bevel that aims to collect a core histological sample by shearing material from the lesion during retrograde motion (Figure 1D) [24].

In a retrospective study comparing 110 patients who had an EBUS using a $22 \mathrm{G}$ needle with 125 patients who had an EBUS using the ProCore ${ }^{\circledR}$ needle, the EBUS core biopsy had a higher sensitivity than standard EBUS-TBNA ( $92 \%$ vs. $77 \%, p=0.001$ ). Additional sampling methods such as mediastinoscopy and CT-guided FNA were obtained in $30 \%$ of patients who underwent standard EBUS-TBNA versus $15 \%$ of those who had EBUS core biopsy $(p=0.006)$ [25]. However, in a prospective trial, Dhooria et al. found no difference in the diagnostic yield of patients with intrathoracic lymphadenopathy with suspected sarcoidosis when these patients were randomized to EBUS-TBNA with the ProCore needle versus the standard $22 \mathrm{G}$ TBNA needle [26]. 

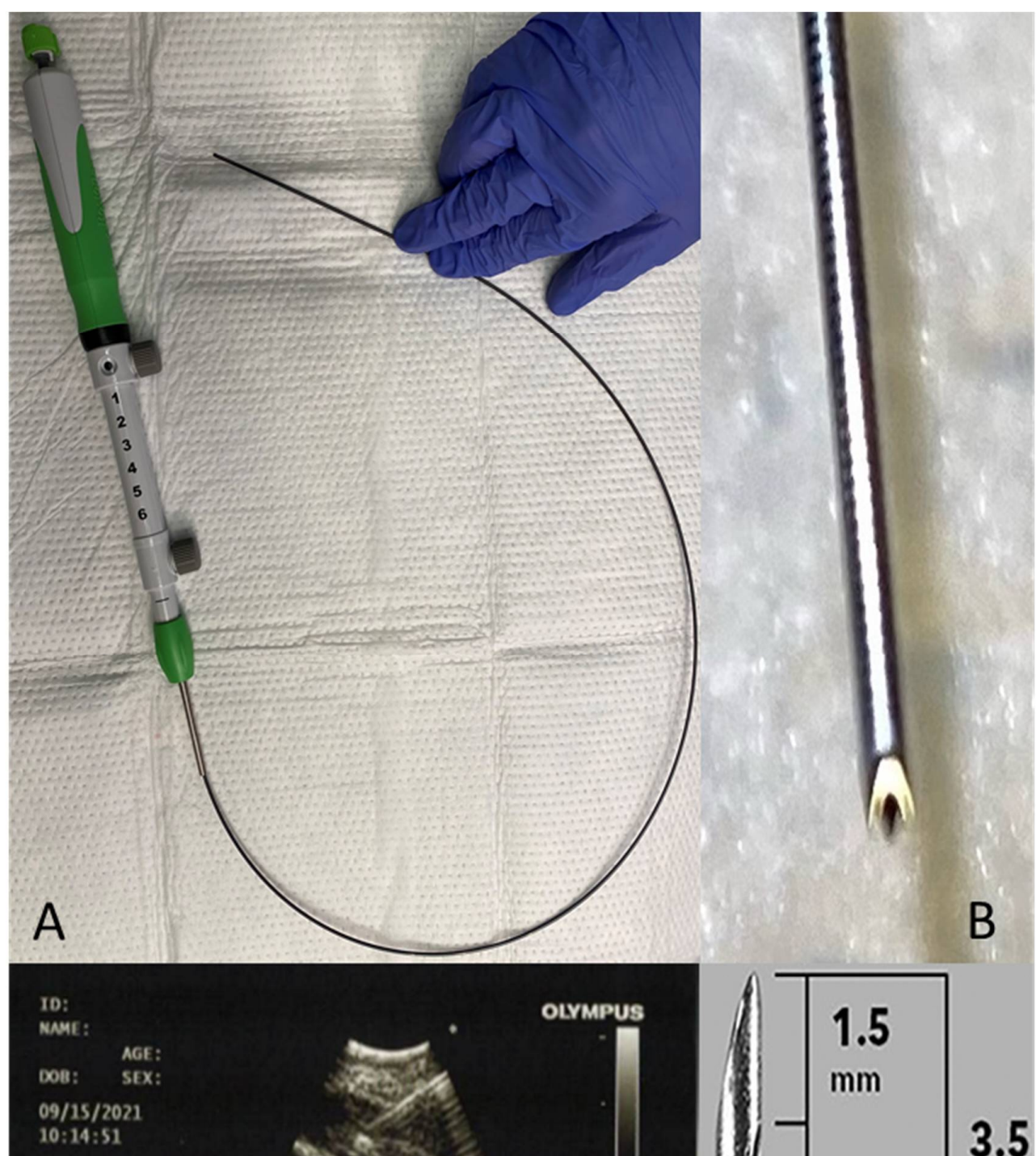

$10: 14: 51$

$10 \mathrm{miz} \quad 4 \mathrm{~cm}$

6:16/19 $\mathrm{I}: 11$

C:7/8 FC:3

L. DeN $: \times 2.0$

IX: $100 x$

MEDIALE

0

(1)
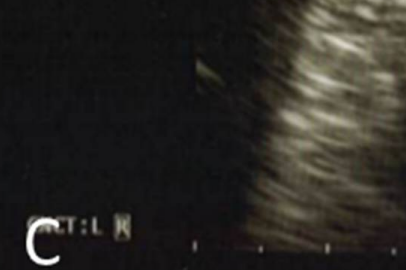

$\mathrm{C}^{\mathrm{C}: \mathrm{K}}$
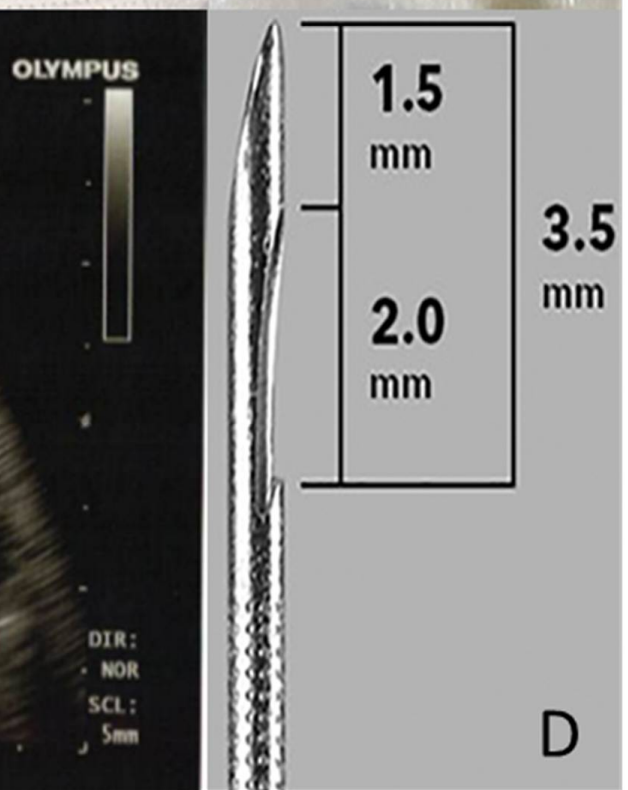

Figure 1. Core biopsy needle. (A) Acquire ${ }^{\circledR} 22$ G FNB needle. (B) Acquire Franseen needle tip. (C) EBUS-FNB of a hilar lymph node. (D) ProCore ${ }^{\circledR}$ needle with reverse bevel (image obtained with permission from John Wiley \& Sons, Inc., Hoboken, NJ, USA) [24].

\subsection{Mini-Forceps Biopsy}

A histological sampling of the lymph node can be done via mini-biopsy forceps, which is introduced through the initial hole made by the TBNA needle (Figure 2A-D). 


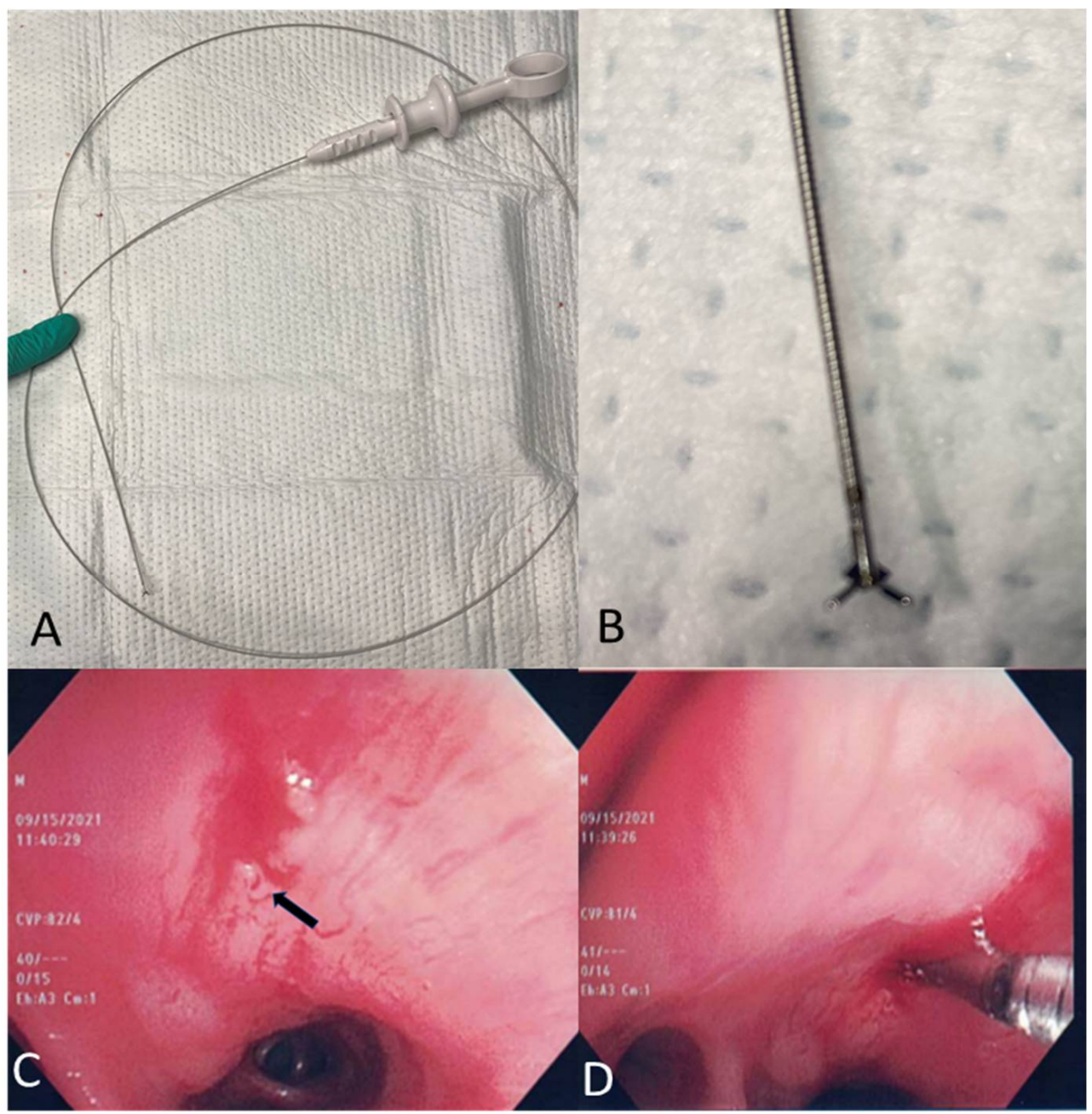

Figure 2. Mini-biopsy forceps. (A) Boston Scientific CoreDxTM Pulmonary Mini-Forceps. (B) Tip of the CoreDxTM Pulmonary Mini-Forceps. (C) Hole (arrow) created in the mucosa by TBNA needle. (D) Mini-forceps passed through the hole for biopsy of mediastinal structures.

Herth et al. evaluated the role of transbronchial forceps biopsy (TBFB) in 75 patients without known or suspected NSCLC. Specimens were acquired from subcarinal lymph nodes larger than $2.5 \mathrm{~cm}$. Sampling was done with a $22 \mathrm{G}$ needle, $19 \mathrm{G}$ needle, and a $1.15 \mathrm{~mm}$ (FB-56D-I; Olympus Ltd., Japan) mini-forceps with a cup opening of $7.3 \mathrm{~mm}$. A diagnosis was obtained in $36 \%, 49 \%$, and $88 \%$ of the cases while using the $22 \mathrm{G}$ needle, $19 \mathrm{G}$ needle, and the mini-forceps, respectively. The mini-forceps diagnostic yield compared with the needle was the highest in patients with sarcoidosis ( $88 \%$ vs. $36 \%, p=0.001)$ and lymphoma ( $81 \%$ vs. $35 \%, p=0.038$ ). No complications occurred [27].

Similarly, Chrissian et al. showed that combining EBUS-TBNA with EBUS-TBFB in a population of 50 patients with a low likelihood of NSCLC resulted in a higher diagnostic yield of $97 \%$ compared with either modality alone (81\% for EBUS-TBNA and $91 \%$ for EBUS-TBFB), with no additional complications [28].

In a retrospective study of 91 patients who had a forceps biopsy with EBUS-TBFB after a non-diagnostic rapid on-site evaluation (ROSE), no difference was seen in the overall diagnostic yield of TBNA versus TBFB. Out of the non-diagnostic TBNA samples on rapid on side evaluation (ROSE) and cell block, subsequent TBFB sampling resulted in additional pathological diagnosis in $16 \%$ of the cases; $67 \%$ of these were non-caseating granulomas. No complications were reported [29].

A meta-analysis of six observational studies included 443 patients in whom TBFB was performed after the initial EBUS-TBNA. Comparing EBUS-TBNA + EBUS-TBFB vs. 
EBUS-TBNA alone, the pooled overall diagnostic yield was $92 \%$ vs. $67 \%(p<0.00001)$, the diagnostic yield for sarcoidosis was $93 \%$ vs. $58 \%(p<0.00001)$, and the diagnostic yield for lymphoma was $86 \%$ vs. $30 \%$ ( $p=0.03$ ). Pneumomediastinum occurred in $1 \%$, pneumothorax in $1 \%$, and bleeding in $0.8 \%$ of the patients [30].

Currently available mini-forceps include the Olympus mini-forceps (FB-56D-I; Olympus Ltd., Tokyo, Japan) with an outer diameter of $1.15 \mathrm{~mm}$ and a cup opening of $7.3 \mathrm{~mm}$ [27], the Boston Scientific "SpyBite biopsy" Forceps (model: M00546270, Natick, MA, USA) with an outer diameter of $1 \mathrm{~mm}$ [29], and the CoreDx ${ }^{\mathrm{TM}}$ Pulmonary Mini-Forceps by Boston Scientific with an outer diameter of $0.96 \mathrm{~mm}$ and a $4.3 \mathrm{~mm}$ jaw opening (Figure 2). The specimen obtained by EBUS-TBFB should be handled as the histology specimen and placed in formalin for fixation or in saline if culture is required [31].

In summary, EBUS-TBFB appears to be complimentary to EBUS-TBNA and can be used when additional tissue is needed for molecular marker studies and in the diagnosis of lesions when the initial sampling with EBUS-TBNA is inadequate or non-diagnostic.

\subsection{Lymph Node Cryobiopsy under EBUS Guidance}

A histological sampling of the lymph node has been reported with the use of a $1.1 \mathrm{~mm}$ cryobiopsy probe placed in the same hole created by the TBNA with a 3 sec freeze time before pulling the probe out. The specimen is thawed in saline and fixed in formalin [32]. In a prospective study of 197 patients undergoing EBUS-TBNA and EBUS cryobiopsy for mediastinal lesions of at least $1 \mathrm{~cm}$, cryobiopsy had higher sensitivity than TBNA in rare tumors $(91 \%$ vs. $25 \% ; p=0.001)$ and benign disorders $(81 \%$ vs. $53 \% ; p=0.04)$. The diagnostic yield was similar in malignant lymphadenopathy. Two cases of pneumothorax and one case of pneumomediastinum were reported [33].

\subsection{EBUS Elastography}

Pathological processes make the tissue harder compared with the normal surrounding structure. Elastography is a recent modality that allows the calculation and visualization of tissue elasticity during EBUS. Data are converted into an RGB (red, green, and blue) color image where hard tissue is shown in blue, medium tissue in green, and soft tissue in red [34]. The images are then superimposed onto the standard grayscale B-mode ultrasound scan [35]. Lesions can be classified as type I, predominantly non-blue; type II, partly blue; and type III, predominantly blue (Figure 3). Types I and III (but not type II) were shown to be highly accurate in predicting benign or malignant disease, respectively $[34,36,37]$.

Quantitative elastography data can also be produced by measuring the strain ratio (SR) of the lesion compared with the normal surrounding tissue. Malignant lymph nodes have a higher SR. An SR > 2.5 had a 100\% sensitivity for predicting malignant lymph nodes [34].

A meta-analysis of 17 studies for differentiating benign versus malignant adenopathy found a pooled sensitivity of 0.90 (95\% confidence interval (CI), 0.84-0.94) and specificity of 0.78 (95\% CI, 0.74-0.81) [38], suggesting that this modality could be important in real-time differentiation of benign versus malignant lymphadenopathy. 
A

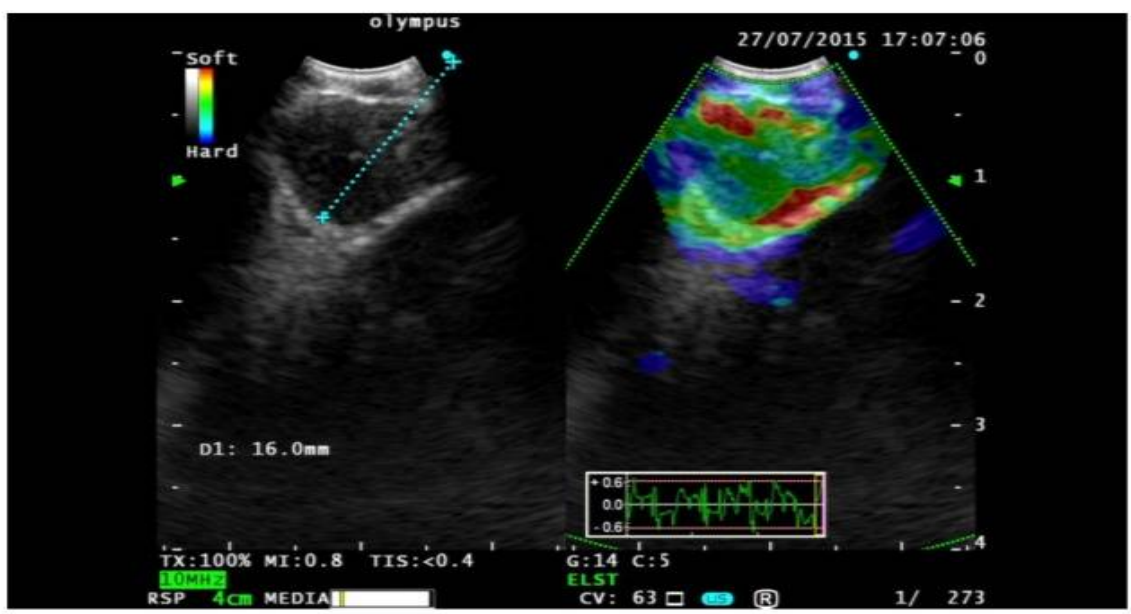

B

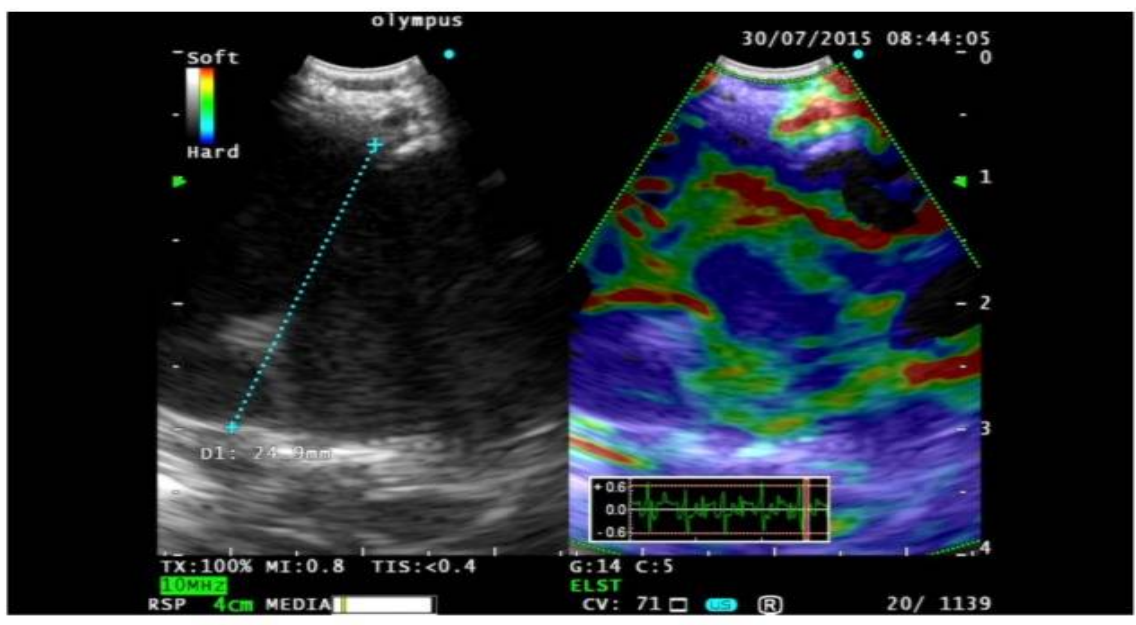

$\mathrm{C}$

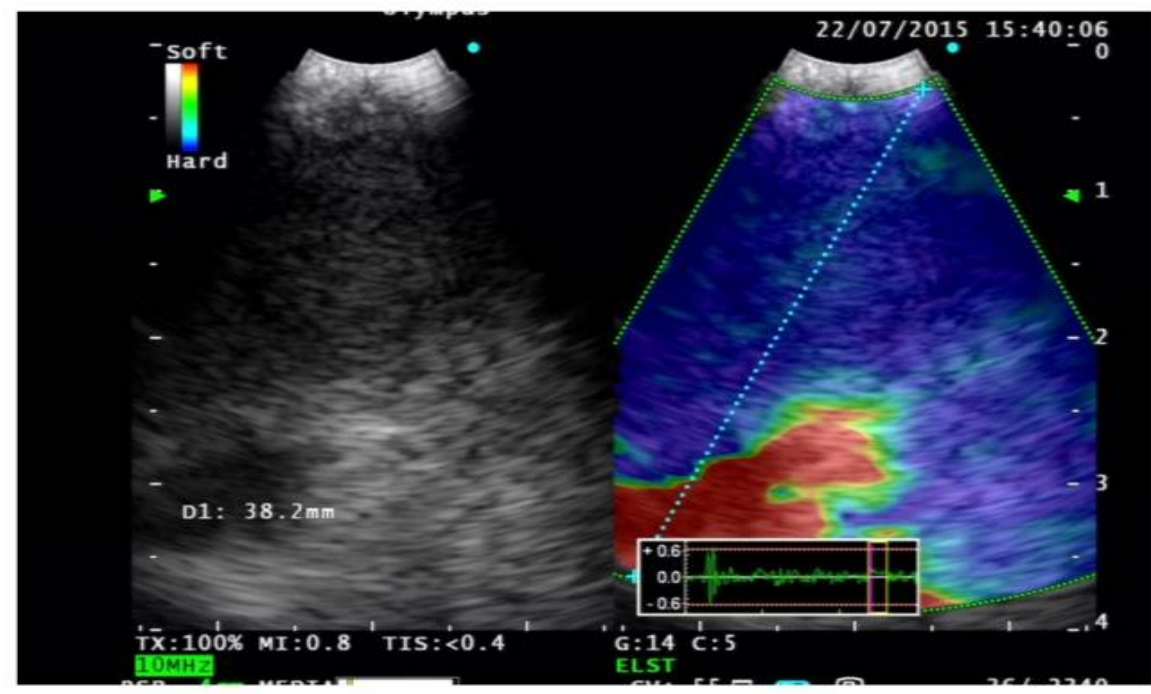

Figure 3. Elastography. (A) Type 1; predominantly non-blue (green, yellow, and red). (B) Type 2; part blue, part non-blue (green, yellow, and red). (C) Type 3 predominantly blue (reproduced with permission from Reference [37]). 


\section{Evaluation and Processing of Cytopathological Material Obtained by EBUS 3.1. Rapid On-Site Evaluation}

ROSE of EBUS-TBNA samples allows for the rapid evaluation of the adequacy of the sample and a preliminary diagnosis before the specimen is completely evaluated. ROSE helps in assessing the adequacy of the sample, determining the need for additional molecular testing, and potentially decreasing the number of procedural sites. Multiple studies have been performed to compare the utility of ROSE for EBUS-TBNA samples [39-42]. Griffin et al. demonstrated, in a retrospective study, that there was no difference in diagnostic yield or number of sampled sites with the use of ROSE [39]. In a prospective small study including 81 patients who underwent EBUS with and without ROSE, Cardoso et al. found that the use of ROSE resulted in a higher rate of adequate samples and diagnostic accuracy, although the difference did not reach statistical significance [42]. In a larger randomized prospective trial of 236 patients undergoing EBUS-TBNA, the diagnostic yield in the ROSE group was significantly higher $(90 \%$ vs. $81 \%, p=0.003)$ and the rate of a suspicious specimen on cytology and non-diagnostic specimen in pathology was significantly lower compared with the non-ROSE group [43]. Another randomized controlled trial of 108 patients showed that ROSE use resulted in a lower puncture number with no increase in the procedure time. Even though the overall diagnostic yield was higher in the ROSE group ( $85 \%$ vs. $75 \%)$, it did not reach statistical significance [44].

Overall, ROSE is a helpful tool to optimize the preparation of the specimen and evaluate the adequacy of lymph node sampling. It may help in increasing the diagnostic yield and avoiding repeated procedures (for additional desired testing) without affecting the total time of the procedure [45].

\subsection{Adequacy of Samples Obtained during EBUS}

Currently, there are no defined standardized criteria to determine the adequacy of a sample obtained with EBUS. In general, a sample is considered adequate when a diagnosis is made, such as granuloma or malignancy even in the absence of lymphoid tissue, or if sufficient benign lymphoid tissue is present [45].

Nayak et al. defined an adequate sample as any smear that contains more than 5 fields with at least 100 lymphocytes per low-power field $(\times 100)$ in a smear PLUS less than 2 groups of bronchial cells per low-power field $(\times 100)$, or the presence of germinal center fragments, irrespective of the above-mentioned criteria [46]. In addition, any smear with positive results such as malignancy or granuloma was considered adequate. Based on the above, each site can be assigned one of the following categories: non-diagnostic, negative for the disease, granulomatous, suspicious for malignancy, or positive for malignancy [46]. In 2016, Choi et al. suggested using a core tissue length of at least $2 \mathrm{~cm}$, presence of malignant cells, anthracotic pigment, or a lymphocyte density of more than 40 per 10 high-power fields (at $\times 40$ magnification) as criteria for an adequate specimen [47].

\subsection{Cell Block and Molecular Testing}

Cell block is a technique to preserve gross pathological specimens using paraffin blocks for histopathological analysis. It allows for the evaluation of cytological architecture and immunochemical staining, thereby allowing for better characterization of the malignancy [48]. Cell block analysis can increase the yield of EBUS-TBNA by $7 \%$ and can generate data for genetic analysis in patients with adenocarcinoma [49]. In 2008, Lee et al. found that a maximum of three passes per lymph node station resulted in a maximal yield for cytopathologic diagnosis [50].

The identification of predictive malignant cell biomarkers in NSCLC has enabled targeted therapies to be utilized for better patient outcomes [51]. Testing for tumor markers such as EGFR, KRAS, and ALK has hence become the standard of care [52]. Once a diagnosis of carcinoma is obtained, extra passes for a cell block should be done for additional studies [45]. 
In a retrospective study from 2013 of 85 patients who underwent EBUS-TBNA, Yarmus et al. showed that a minimum of four passes per lymph node station is required to provide an adequate amount of specimen when advanced molecular marker analysis is limited to EGFR, KRAS sequencing, and $A L K$ fluorescence in situ hybridization [53]. With the increased availability of additional targetable biomarkers to drive treatment decisions, it remains unclear what is the optimal number of passes that should be obtained [45].

EBUS-TBNA can provide adequate DNA sampling for next-generation sequencing (NGS). The amount of DNA needed for this modality depends on the NGS technique used. Cho et al. found the average total DNA amount from EBUS sampling to be $1971 \mathrm{ng}$ with a range of $100 \mathrm{ng}$ to $10,340 \mathrm{ng}$ [54].

In general, the adequacy of EBUS-TBNA for molecular analysis depends on the sample size, cellularity, tumor cell fraction in the samples, the presence of contaminants such as blood or bronchial cells, and the sensitivity of the molecular testing platform [45,55]. Trisolini et al. evaluated the role of ROSE in molecular profiling in NSCLC and found that complete genotyping was achieved in $90 \%$ of the ROSE arm compared with $80 \%$ of the non-ROSE arm [56]. Although this difference did not reach statistical significance, it may be clinically relevant. A close collaboration between the molecular lab and the cytopathologist is required to determine sample adequacy for molecular testing.

Overall, the recent literature shows that lymph node sampling via EBUS-TBNA can provide enough material at least $92 \%$ of the time for a complete genomic test, which included several biomarkers by NGS and nCounter [57], and more than $94 \%$ of the time for immunohistochemical testing for PD-L1 [57,58].

\section{Optimizing the Diagnostic Yield of EBUS in Lymphoma and Sarcoidosis} 4.1. Lymphoma

EBUS-TBNA is a relatively safe procedure for the evaluation of mediastinal/hilar lymphadenopathy, with a reported diagnostic yield of up to $90 \%$ [59]. That yield is lower for lymphoma. Studies looking at the yield of EBUS-TBNA for lymphoma have included very low numbers of patients.

In one of the largest studies, which included 75 patients with a final diagnosis of lymphoma, EBUS-TBNA was able to establish a diagnosis in $84 \%$ of the patients and was able to subtype lymphoma in $67 \%$ of de novo cases and in $81 \%$ of the relapsed cases [60]. The lowest yield was in patients with Hodgkin's lymphoma compared with non-Hodgkin's lymphoma [60], and in newly diagnosed compared with recurrent lymphoma [60,61]. Moonim et al. prospectively reviewed 100 cases of suspected lymphoma sampled by EBUS-TBNA. A final diagnosis was achieved in $88 \%$ of the de novo lymphoma cases and $100 \%$ of the relapsed cases. The reported diagnostic accuracy was $91 \%$ with the lowest sensitivity (79\%) reported for Hodgkin's lymphoma [62]. Dayan et al. reported similar results with a diagnostic accuracy of $92 \%$ [63].

While EBUS-TBNA can be the first diagnostic modality, EBUS-TBFB and EBUS core biopsies might be able to provide larger histopathological tissue to help in subtyping lymphoma $[27,28]$. In one meta-analysis of 443 patients, adding mini-forceps biopsy to EBUS-TBNA increased the diagnostic yield significantly from $30 \%$ to $86 \%(p=0.03)$ [30].

Flow cytometry is of particular importance in the immunological phenotyping of lymphomas [64]. Since diagnosis and subtyping are essential to provide treatment for patients with lymphoma, negative results should not exclude lymphoma [61]. Surgical excision remains the gold standard [65].

\subsection{Sarcoidosis}

EBUS-TBNA is the first choice for pathological confirmation of sarcoidosis [66]. It has a pooled sensitivity of more than $80 \%$ for diagnosing sarcoidosis [67], significantly higher than transbronchial lung biopsy (TBB) or endobronchial biopsy (EBB) alone. The combination of EBUS-TBNA with TBB and EBB results in a significant increase in the diagnostic yield (90\%) for the diagnosis of stages I and II sarcoidosis [68-70]. In addition to 
improving the diagnostic yield, EBUS-TBNA with rapid on-site evaluation may alleviate the need to perform unnecessary TBB [71].

In a prospective study of 109 patients who underwent EBUS-TBNA for suspected stages I and II sarcoidosis, the cumulative yields for detecting non-caseating granulomas through the first, second, third, fourth, fifth, and sixth passes for the main target lesion were $63 \%, 75 \%, 82 \%, 85 \%, 86 \%$, and $88 \%$, respectively. The increase was statistically significant up to pass \#4 [72]. A higher yield was associated with sampling nodes with a short axis of more than $1 \mathrm{~cm}$, and with stage I compared with stage II sarcoidosis [73]. The number of nodes sampled appears to increase the yield in some studies [74], but not in others [73].

Procedurally, the most common endosonographic findings from sarcoidosis lymph nodes include the presence of a homogeneous texture, oval shape, a conglomeration of lymph nodes [75,76], distinct margins [75,76], and increased non-hilar perfusion [76]. The presence of the necrosis sign and absence of the clustered formation were independent factors predictive of tuberculous nodes as opposed to sarcoidosis [76].

There was no difference in the diagnostic yield in relation to needle size $(22 \mathrm{G}$ vs. 25 G [9], or 21 G vs. 22 G [77]) in patients suspected of having sarcoidosis. Similarly, the number of agitations of the EBUS needle (10 vs. 20) did not influence the diagnostic yield or the specimen adequacy in this population [78]. However, adding mini-forceps biopsy to EBUS-TBNA increased the diagnostic yield significantly from $58 \%$ to $93 \%(p<0.00001)$ in one meta-analysis of 443 patients [30].

\section{Conclusions}

EBUS-TBNA remains the first-line minimally invasive test to evaluate mediastinal and hilar adenopathy. Since its introduction, the procedure has been refined to eliminate unnecessary steps and reduce the procedure time while optimizing the diagnostic yield. In areas where no difference between the different techniques was found, larger high-quality randomized controlled trials are recommended. In addition to providing nodal staging, EBUS-TBNA allows the acquisition of molecular markers that are essential in guiding the choice of therapy in patients with non-small cell lung cancer. It also provides an excellent diagnostic yield in stages I and II sarcoidosis. Newer tools such as core needles and miniforceps are now available, and they appear to increase the histopathological specimen size and possibly the diagnostic yield in patients with lymphoma and benign diseases, therefore reducing the need for more invasive interventions such as mediastinoscopy.

Table 1. Summary of the effects of different interventions on the diagnostic yield of EBUS. LN $=$ lymph node. * Trials comparing different techniques on the same LN.

\begin{tabular}{|c|c|c|}
\hline Intervention & Type of Study and Number of Patients/LN ( $n$ ) & Overall Findings \\
\hline $\begin{array}{l}\text { Needle size } \\
21 \text { vs. } 22 \mathrm{G}\end{array}$ & $\begin{array}{ll}\text { - } & \text { Retrospective study ( } n=1235 \text { patients) [6] } \\
\text { - } & \text { Systematic review [2] }\end{array}$ & $\begin{array}{l}\text { - No statistically significant difference in } \\
\text { diagnostic yield }\end{array}$ \\
\hline $\begin{array}{l}\text { Needle size } \\
22 \text { vs. } 25 \mathrm{G}\end{array}$ & $\begin{array}{ll}\text { - } & \text { Prospective randomized crossover study } \\
& (n=102 \text { patients) [7] } \\
\text { - } & \text { Retrospective propensity-matched study } \\
& (n=158 \text { LN) [9] }\end{array}$ & $\begin{array}{l}\text { - No statistically significant difference in } \\
\text { diagnostic yield }\end{array}$ \\
\hline $\begin{array}{l}\text { Needle size } \\
21 \text { vs. } 25 \mathrm{G}\end{array}$ & - $\quad$ * Prospective study ( $n=50$ patients) [10] & $\begin{array}{l}\text { - No statistically significant difference in } \\
\text { diagnostic yield }\end{array}$ \\
\hline $\begin{array}{l}\text { Needle size } \\
22 \text { vs. } 19 \mathrm{G}\end{array}$ & $\begin{array}{ll}- & \text { * Single-center prospective study }(n=27)[11] \\
- & \text { Randomized controlled trial }(n=78)[12] \\
\text { - } & \text { Prospective randomized trial }(n=107 \text { patients }) \\
& {[14]}\end{array}$ & 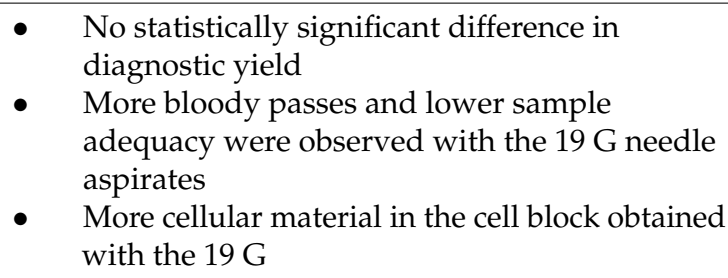 \\
\hline
\end{tabular}


Table 1. Cont.

\begin{tabular}{llll}
\hline Intervention & Type of Study and Number of Patients/LN $(n)$ & Overall Findings \\
\hline $\begin{array}{l}\text { Needle size } \\
21 \text { vs. } 19 \mathrm{G}\end{array}$ & $\bullet \quad$ * Prospective study $(n=47$ patients) [13] & $\begin{array}{l}\text { No statistically significant difference in } \\
\text { diagnostic yield } \\
\text { More cellular material in the cell block obtained } \\
\text { with the 19 G }\end{array}$ \\
\hline $\begin{array}{l}\text { Needle size } \\
19 \text { vs. } 21 \text { vs. 22 G }\end{array}$ & $\bullet \quad$ Retrospective study ( $n=300$ patients) [15] & $\begin{array}{l}\text { A higher proportion of lymphoma and benign } \\
\text { disease found in LN sampled with the 19 G } \\
\text { compared with 21 G and 22 G }\end{array}$ \\
\hline
\end{tabular}

- $\quad$ Prospective, randomized, non-inferiority trial comparing no suction to $10 \mathrm{~mL}$ and $20 \mathrm{~mL}$ of suction ( $n=323$ lymph node) [16]

- $\quad$ * Prospective, non-inferiority study of suction

Stylet use and suction versus no suction ( $n=26$ patients) [17]

- Prospective randomized trial of suction versus no suction ( $n=115$ patients) [18]

- $\quad$ * Randomized controlled trial comparing suction-stylet, suction-no stylet, and stylet-no suction ( $n=97$ patients) [19]

$\begin{array}{ll}\begin{array}{l}\text { Fanning vs. no } \\ \text { fanning }\end{array} & -\quad \begin{array}{l}\text { Sample study on ex vivo tissue models } \\ (n=18 \text { targets })[21]\end{array}\end{array}$
fanning

Core needle versus $22 \mathrm{G}$

- $\quad$ Retrospective study ( $n=235$ patients) [25]
- No statistically significant difference in diagnostic yield

- Suction increased core tissue acquisition rate compared with no suction

\begin{tabular}{|c|c|c|}
\hline 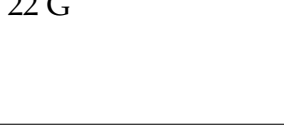 & & $\begin{array}{l}\text { mediastinoscopy and CT-guided FNA were } \\
\text { obtained in fewer patients who underwent } \\
\text { EBUS core biopsy. }\end{array}$ \\
\hline Number of passes & - $\quad$ Prospective study ( $n=102$ patients) [50] & $\begin{array}{l}\text { - A maximum of three passes per lymph node } \\
\text { station results in a maximal yield for } \\
\text { cytopathologic diagnosis. }\end{array}$ \\
\hline ROSE vs. no ROSE & $\begin{array}{ll}\text { - } & \text { Retrospective study } \\
& (n=294 \text { EBUS specimens) [39] } \\
\text { - } & \text { Randomized controlled trial } \\
& (n=236 \text { patients) [43] }\end{array}$ & $\begin{array}{l}\text { - } \quad \text { Conflicting studies about the diagnostic yield } \\
\text { ROSE resulted in a lower puncture number } \\
\text { with no increase in the procedure time }\end{array}$ \\
\hline Cell block & - $\quad$ Retrospective review ( $n=85$ patients) [53] & $\begin{array}{l}\text { A minimum of four passes per lymph node } \\
\text { station is required for cell block analysis }\end{array}$ \\
\hline $\begin{array}{l}\text { Mini-forceps vs. } \\
\text { TBNA }\end{array}$ & $\begin{array}{l}\text { - } \quad \text { * Prospective study evaluating } 22 \mathrm{G}, 19 \mathrm{G} \text {, and } \\
\text { mini-forceps biopsy }(n=75)[27] \\
\text { - } \quad \text { * Prospective study }(n=50 \text { patients })[28]\end{array}$ & $\begin{array}{l}\text { - Mini-forceps resulted in a higher diagnostic } \\
\text { yield in sarcoidosis and lymphoma }\end{array}$ \\
\hline $\begin{array}{l}\text { Lymph node } \\
\text { cryobiopsy vs. } \\
\text { TBNA }\end{array}$ & $\begin{array}{l}\text { - Randomized controlled trial }(\mathrm{n}=197 \text { patients) } \\
\text { [33] }\end{array}$ & $\begin{array}{l}\text { - Cryobiopsy had a higher sensitivity in benign } \\
\text { but not in malignant lymphadenopathy }\end{array}$ \\
\hline Elastography & $\begin{array}{ll}\text { - } & \text { Prospective study }(n=120 \mathrm{LN})[34] \\
\text { - } & \text { Retrospective study }(n=75 \mathrm{LN})[36] \\
\text { - } & \text { Retrospective study }(n=78 \mathrm{LN})[37]\end{array}$ & $\begin{array}{l}\text { - High correlation of non-blue and } \\
\text { predominantly blue lesions with benign and } \\
\text { malignant diseases, respectively }\end{array}$ \\
\hline
\end{tabular}

Author Contributions: Conception and design: H.A.Y. and K.H.; Collection and assembly of data: H.A.J. and S.M.F.; Manuscript writing: H.A.J., S.M.F., T.A., J.I.K., K.H. and H.A.Y.; Final approval of manuscript: all authors. All authors have read and agreed to the published version of the manuscript.

Funding: This research received no external funding.

Institutional Review Board Statement: Not applicable.

Informed Consent Statement: Not applicable.

Conflicts of Interest: The authors declare no conflict of interest. 


\section{References}

1. Hürter, T.; Hanrath, P. Endobronchial sonography: Feasibility and preliminary results. Thorax 1992, 47, 565-567. [CrossRef]

2. Wahidi, M.M.; Herth, F.; Yasufuku, K.; Shepherd, R.W.; Yarmus, L.; Chawla, M.; Lamb, C.; Casey, K.R.; Patel, S.; Silvestri, G.A.; et al. Technical Aspects of Endobronchial Ultrasound-Guided Transbronchial Needle Aspiration: CHEST Guideline and Expert Panel Report. Chest 2016, 149, 816-835. [CrossRef]

3. Silvestri, G.A.; Gonzalez, A.V.; Jantz, M.A.; Margolis, M.L.; Gould, M.K.; Tanoue, L.T.; Harris, L.J.; Detterbeck, F.C. Methods for staging non-small cell lung cancer: Diagnosis and management of lung cancer, 3rd ed: American College of Chest Physicians evidence-based clinical practice guidelines. Chest 2013, 143, e211S-e250S. [CrossRef] [PubMed]

4. Canneto, B.; Ferraroli, G.; Falezza, G.; Infante, M.V. Ideal conditions to perform EBUS-TBNA. J. Thorac. Dis. 2017, 9, S414-S417. [CrossRef]

5. $\quad$ Casal, R.F.; Lazarus, D.R.; Kuhl, K.; Nogueras-González, G.; Perusich, S.; Green, L.K.; Ost, D.E.; Sarkiss, M.; Jimenez, C.A.; Eapen, G.A.; et al. Randomized Trial of Endobronchial Ultrasound-guided Transbronchial Needle Aspiration under General Anesthesia versus Moderate Sedation. Am. J. Respir. Crit. Care Med. 2015, 191, 796-803. [CrossRef]

6. Yarmus, L.B.; Akulian, J.; Lechtzin, N.; Yasin, F.; Kamdar, B.; Ernst, A.; Ost, D.E.; Ray, C.; Greenhill, S.R.; Jimenez, C.A.; et al. Comparison of 21-Gauge and 22-Gauge Aspiration Needle in Endobronchial Ultrasound-Guided Transbronchial Needle Aspiration: Results of the American College of Chest Physicians Quality Improvement Registry, Education, and Evaluation Registry. Chest 2013, 143, 1036-1043. [CrossRef] [PubMed]

7. Sakai, T.; Udagawa, H.; Kirita, K.; Nomura, S.; Itotani, R.; Tamiya, Y.; Sugimoto, A.; Ota, T.; Naito, T.; Izumi, H.; et al. Comparison of the efficiency of endobronchial ultrasound-guided transbronchial needle aspiration using a 22G needle versus 25G needle for the diagnosis of lymph node metastasis in patients with lung cancer: A prospective randomized, crossover study. Transl. Lung Cancer Res. 2021, 10, 3745-3758. [CrossRef]

8. Sakai, T.; Udagawa, H.; Kirita, K.; Nomura, S.; Sugimoto, A.; Itotani, R.; Tamiya, Y.; Izumi, H.; Nosaki, K.; Ikeda, T.; et al. P02.03 Comparison of the Efficiency of 22G Versus 25G Needle in EBUS-TBNA for Diagnosis of Lung Cancer; A Prospective Randomized, Crossover Study. J. Thorac. Oncol. 2021, 16, S247. [CrossRef]

9. Di Felice, C.; Young, B.; Matta, M. Comparison of specimen adequacy and diagnostic accuracy of a 25-gauge and 22-gauge needle in endobronchial ultrasound-guided transbronchial needle aspiration. J. Thorac. Dis. 2019, 11, 3643-3649. [CrossRef]

10. Sood, R.; Alape, D.; Thakkar, D.; Shadchehr, S.; Acash, G.; Tronic, B.J.; Lamb, C.R. Comparison of Sample Adequacy and Diagnostic Yield of the 21-G and 25-G EBUS TBNA Needles. J. Bronchol. Interv. Pulmonol. 2021. [CrossRef] [PubMed]

11. Chaddha, U.; Ronaghi, R.; Elatre, W.; Chang, C.-F.; Mahdavi, R. Comparison of sample adequacy and diagnostic yield of 19-and 22-G EBUS-TBNA needles. J. Bronchol. Interv. Pulmonol. 2018, 25, 264-268. [CrossRef]

12. Dooms, C.; Vander Borght, S.; Yserbyt, J.; Testelmans, D.; Wauters, E.; Nackaerts, K.; Vansteenkiste, J.; Verbeken, E.; Weynand, B A Randomized Clinical Trial of Flex 19G Needles versus 22G Needles for Endobronchial Ultrasonography in Suspected Lung Cancer. Respir. Int. Rev. Thorac. Dis. 2018, 96, 275-282. [CrossRef]

13. Pickering, E.M.; Holden, V.K.; Heath, J.E.; Verceles, A.C.; Kalchiem-Dekel, O.; Sachdeva, A. Tissue acquisition during EBUS-TBNA. J. Bronchol. Interv. Pulmonol. 2019, 26, 237-244. [CrossRef] [PubMed]

14. Wolters, C.; Darwiche, K.; Franzen, D.; Hager, T.; Bode-Lesnievska, B.; Kneuertz, P.J.; He, K.; Koenig, M.; Freitag, L.; Wei, L.; et al. A Prospective, Randomized Trial for the Comparison of 19-G and 22-G Endobronchial Ultrasound-Guided Transbronchial Aspiration Needles; Introducing a Novel End Point of Sample Weight Corrected for Blood Content. Clin Lung Cancer 2019, 20, e265-e273. [CrossRef] [PubMed]

15. Jones, R.C.; Bhatt, N.; Medford, A.R.L. The effect of 19-gauge endobronchial ultrasound-guided transbronchial needle aspiration biopsies on characterisation of malignant and benign disease. The Bristol experience. Monaldi Arch. Chest Dis. 2018, 88, 915. [CrossRef] [PubMed]

16. Mohan, A.; Iyer, H.; Madan, K.; Hadda, V.; Mittal, S.; Tiwari, P.; Jain, D.; Pandey, R.; Garg, A.; Guleria, R. A Randomized Comparison of Sample Adequacy and Diagnostic Yield of EBUS-TBNA using various Suction Pressures. Res. Sq. 2021. [CrossRef]

17. Harris, K.; Maroun, R.; Attwood, K.; Chalhoub, M. Comparison of cytologic accuracy of endobronchial ultrasound transbronchial needle aspiration using needle suction versus no suction. Endosc. Ultrasound 2015, 4, 115-119. [CrossRef]

18. Casal, R.F.; Staerkel, G.A.; Ost, D.; Almeida, F.A.; Uzbeck, M.H.; Eapen, G.A.; Jimenez, C.A.; Nogueras-Gonzalez, G.M.; Sarkiss, M.; Morice, R.C. Randomized clinical trial of endobronchial ultrasound needle biopsy with and without aspiration. Chest 2012, 142, 568-573. [CrossRef]

19. Lin, X.; Ye, M.; Li, Y.; Ren, J.; Lou, Q.; Li, Y.; Jin, X.; Wang, K.-P.; Chen, C. Randomized controlled trial to evaluate the utility of suction and inner-stylet of EBUS-TBNA for mediastinal and hilar lymphadenopathy. BMC Pulm. Med. 2018, 18, 192. [CrossRef]

20. Bang, J.Y.; Magee, S.H.; Ramesh, J.; Trevino, J.M.; Varadarajulu, S. Randomized trial comparing fanning with standard technique for endoscopic ultrasound-guided fine-needle aspiration of solid pancreatic mass lesions. Endoscopy 2013, 45, 445-450. [CrossRef]

21. Parthiban, S.; Sczaniecka, A.; Dillard, D.; Gonzalez, X. Comparison of Fanning and No-Fanning Sampling Techniques for Endobronchial Ultrasound-Guided Transbronchial Needle Aspiration in an Ex Vivo Tissue Model. Chest 2017, 152, A964. [CrossRef]

22. El, H.I.; Wu, H.; Reuss, S.; Randolph, M.; Harris, A.; Gromski, M.A.; Al-Haddad, M. Prospective Assessment of the Performance of a New Fine Needle Biopsy Device for EUS-Guided Sampling of Solid Lesions. Clin. Endosc. 2018, 51, 576-583. [CrossRef] 
23. Balwan, A.; Bixby, B.; Grotepas, C.; Witt, B.L.; Iravani, A.; Ansari, S.; Reddy, C.B. Core needle biopsy with endobronchial ultrasonography: Single center experience with 100 cases. J. Am. Soc. Cytopathol. 2020, 9, 249-253. [CrossRef]

24. Yang, L.; Gu, Y.; Wang, H.; Yu, D.; Zhang, H.; Wang, H. Novel ProCore 25-gauge needle for endobronchial ultrasound-guided transbronchial needle aspiration reduces the puncture time and frequency, with comparable diagnostic rate for mediastinal and hilar lymphadenopathy. Thorac. Cancer 2020, 11, 748-753. [CrossRef]

25. McCracken, D.J.; Bailey, M.; McDermott, M.-T.; McManus, T.E. A retrospective analysis comparing the use of ProCore ${ }^{\circledR}$ with standard fine needle aspiration in endobronchial ultrasound-guided transbronchial needle aspiration (EBUS-TBNA). Ir. J. Med. Sci. 2019, 188, 85-88. [CrossRef]

26. Dhooria, S.; Sehgal, I.S.; Prasad, K.T.; Muthu, V.; Gupta, N.; Bal, A.; Ram, B.; Aggarwal, A.N.; Agarwal, R. Diagnostic yield and safety of the ProCore versus the standard EBUS-TBNA needle in subjects with suspected sarcoidosis. Expert Rev. Med. Devices 2021, 18, 211-216. [CrossRef]

27. Herth, F.J.; Morgan, R.K.; Eberhardt, R.; Ernst, A. Endobronchial ultrasound-guided miniforceps biopsy in the biopsy of subcarinal masses in patients with low likelihood of non-small cell lung cancer. Ann. Thorac. Surg. 2008, 85, 1874-1878. [CrossRef] [PubMed]

28. Chrissian, A.; Misselhorn, D.; Chen, A. Endobronchial-ultrasound guided miniforceps biopsy of mediastinal and hilar lesions. Ann. Thorac. Surg. 2011, 92, 284-288. [CrossRef]

29. Shiari, A.; Aljundi, L.; Boshara, P.; Zein, R.; Zalt, M. Miniforceps EBUS-guided lymph node biopsy: Impact on diagnostic yield. Adv. Respir. Med. 2021, 89, 37-42. [CrossRef]

30. Agrawal, A.; Ghori, U.; Chaddha, U.; Murgu, S. Combined EBUS-IFB and EBUS-TBNA vs EBUS-TBNA alone for intrathoracic adenopathy: A Meta-analysis. Ann. Thorac. Surg. 2021. [CrossRef] [PubMed]

31. Cheng, G.; Mahajan, A.; Oh, S.; Benzaquen, S.; Chen, A. Endobronchial ultrasound-guided intranodal forceps biopsy (EBUS-IFB)technical review. J. Thorac. Dis. 2019, 11, 4049-4058. [CrossRef] [PubMed]

32. Gonuguntla, H.K.; Shah, M.; Gupta, N.; Agrawal, S.; Poletti, V.; Nacheli, G.C. Endobronchial ultrasound-guided transbronchial cryo-nodal biopsy: A novel approach for mediastinal lymph node sampling. Respirol. Case Rep. 2021, 9, e00808. [CrossRef] [PubMed]

33. Zhang, J.; Guo, J.-R.; Huang, Z.-S.; Fu, W.-L.; Wu, X.-L.; Wu, N.; Kuebler, W.M.; Herth, F.J.F.; Fan, Y. Transbronchial mediastinal cryobiopsy in the diagnosis of mediastinal lesions: A randomised trial. Eur. Respir. J. 2021. [CrossRef]

34. Korrungruang, P.; Boonsarngsuk, V. Diagnostic value of endobronchial ultrasound elastography for the differentiation of benign and malignant intrathoracic lymph nodes. Respirology 2017, 22, 972-977. [CrossRef]

35. Saftoiu, A.; Vilman, P. Endoscopic ultrasound elastography-A new imaging technique for the visualization of tissue elasticity distribution. J. Gastrointestin Liver Dis. 2006, 15, 161-165.

36. Izumo, T.; Sasada, S.; Chavez, C.; Matsumoto, Y.; Tsuchida, T. Endobronchial ultrasound elastography in the diagnosis of mediastinal and hilar lymph nodes. Jpn. J. Clin. Oncol. 2014, 44, 956-962. [CrossRef]

37. Huang, H.; Huang, Z.; Wang, Q.; Wang, X.; Dong, Y.; Zhang, W.; Zarogoulidis, P.; Man, Y.-G.; Schmidt, W.H.; Bai, C. Effectiveness of the Benign and Malignant Diagnosis of Mediastinal and Hilar Lymph Nodes by Endobronchial Ultrasound Elastography. J. Cancer 2017, 8, 1843-1848. [CrossRef]

38. Wu, J.; Sun, Y.; Wang, Y.; Ge, L.; Jin, Y.; Wang, Z. Diagnostic value of endobronchial ultrasound elastography for differentiating benign and malignant hilar and mediastinal lymph nodes: A systematic review and meta-analysis. Med. Ultrason 2021. [CrossRef]

39. Griffin, A.C.; Schwartz, L.E.; Baloch, Z.W. Utility of on-site evaluation of endobronchial ultrasound-guided transbronchial needle aspiration specimens. Cytojournal 2011, 8, 20. [CrossRef] [PubMed]

40. Mallya, V.; Kumar, S.P.; Meganathan, P.; Shivkumar, S.; Mehta, R. The utility of ROSE (rapid on-site evaluation) in endobronchial ultrasound (EBUS)-guided transbronchial needle aspiration (TBNA): Is the picture rosy? J. Cytol. 2015, 32, 230-233. [CrossRef]

41. Şimon, M.; Pop, B.; Toma, I.L.; Vallasek, A.K.; Şimon, I. The use of EBUS-TBNA and ROSE in the diagnosis of lung cancer. Rom J. Morphol. Embryol. 2017, 58, 79-87.

42. Haranguş, A.; Berindan-Neagoe, I.; Toma, L.; Şimon, I.; Pop, O.; Şimon, M. EBUS in optimizing non-small cell lung cancer diagnosis and treatment. Med. Pharm. Rep. 2021, 94, 176-184. [CrossRef] [PubMed]

43. Guo, H.; Liu, S.; Guo, J.; Li, B.; Li, W.; Lu, Z.; Sun, J.; Zhang, B.; Yu, J. Rapid on-site evaluation during endobronchial ultrasoundguided transbronchial needle aspiration for the diagnosis of hilar and mediastinal lymphadenopathy in patients with lung cancer. Cancer Lett. 2016, 371, 182-186. [CrossRef] [PubMed]

44. Oki, M.; Saka, H.; Kitagawa, C.; Kogure, Y.; Murata, N.; Adachi, T.; Ando, M. Rapid on-site cytologic evaluation during endobronchial ultrasound-guided transbronchial needle aspiration for diagnosing lung cancer: A randomized study. Respir. Int. Rev. Thorac. Dis. 2013, 85, 486-492. [CrossRef]

45. Jain, D.; Allen, T.C.; Aisner, D.L.; Beasley, M.B.; Cagle, P.T.; Capelozzi, V.L.; Hariri, L.P.; Lantuejoul, S.; Miller, R.; Mino-Kenudson, M.; et al. Rapid On-Site Evaluation of Endobronchial Ultrasound-Guided Transbronchial Needle Aspirations for the Diagnosis of Lung Cancer: A Perspective From Members of the Pulmonary Pathology Society. Arch. Pathol. Lab. Med. 2018, 142, 253-262. [CrossRef]

46. Nayak, A.; Sugrue, C.; Koenig, S.; Wasserman, P.G.; Hoda, S.; Morgenstern, N.J. Endobronchial ultrasound-guided transbronchial needle aspirate (EBUS-TBNA): A proposal for on-site adequacy criteria. Diagn. Cytopathol. 2012, 40, 128-137. [CrossRef] 
47. Choi, S.M.; Lee, A.R.; Choe, J.Y.; Nam, S.J.; Chung, D.H.; Lee, J.; Lee, C.H.; Lee, S.M.; Yim, J.J.; Yoo, C.G.; et al. Adequacy Criteria of Rapid On-Site Evaluation for Endobronchial Ultrasound-Guided Transbronchial Needle Aspiration: A Simple Algorithm to Assess the Adequacy of ROSE. Ann. Thorac. Surg. 2016, 101, 444-450. [CrossRef] [PubMed]

48. Krogerus, L.; Kholová, I. Cell Block in Cytological Diagnostics: Review of Preparatory Techniques. Acta Cytol. 2018, 62, 237-243. [CrossRef] [PubMed]

49. Sanz-Santos, J.; Serra, P.; Andreo, F.; Llatjós, M.; Castellà, E.; Monsó, E. Contribution of cell blocks obtained through endobronchial ultrasound-guided transbronchial needle aspiration to the diagnosis of lung cancer. BMC Cancer 2012, 12, 34. [CrossRef]

50. Lee, H.S.; Lee, G.K.; Lee, H.S.; Kim, M.S.; Lee, J.M.; Kim, H.Y.; Nam, B.H.; Zo, J.I.; Hwangbo, B. Real-time endobronchial ultrasound-guided transbronchial needle aspiration in mediastinal staging of non-small cell lung cancer: How many aspirations per target lymph node station? Chest 2008, 134, 368-374. [CrossRef]

51. Planchard, D.; Popat, S.; Kerr, K.; Novello, S.; Smit, E.F.; Faivre-Finn, C.; Mok, T.S.; Reck, M.; Van Schil, P.E.; Hellmann, M.D.; et al. Metastatic non-small cell lung cancer: ESMO Clinical Practice Guidelines for diagnosis, treatment and follow-up. Ann. Oncol. 2018, 29, iv192-iv237. [CrossRef]

52. Reck, M.; Rabe, K.F. Precision Diagnosis and Treatment for Advanced Non-Small-Cell Lung Cancer. N. Engl. J. Med. 2017, 377, 849-861. [CrossRef] [PubMed]

53. Yarmus, L.; Akulian, J.; Gilbert, C.; Feller-Kopman, D.; Lee, H.J.; Zarogoulidis, P.; Lechtzin, N.; Ali, S.Z.; Sathiyamoorthy, V. Optimizing endobronchial ultrasound for molecular analysis. How many passes are needed? Ann. Am. Thorac. Soc. 2013, 10, 636-643. [CrossRef]

54. Cho, M.; Ahn, S.; Hong, M.; Bang, H.; van Vrancken, M.; Kim, S.; Lee, J.; Park, S.H.; Park, J.O.; Park, Y.S.; et al. Tissue recommendations for precision cancer therapy using next generation sequencing: A comprehensive single cancer center's experiences. Oncotarget 2017, 8, 42478-42486. [CrossRef] [PubMed]

55. Righi, L.; Franzi, F.; Montarolo, F.; Gatti, G.; Bongiovanni, M.; Sessa, F.; La Rosa, S. Endobronchial ultrasound-guided transbronchial needle aspiration (EBUS-TBNA)-from morphology to molecular testing. J. Thorac. Dis. 2017, 9, S395-S404. [CrossRef]

56. Trisolini, R.; Cancellieri, A.; Tinelli, C.; de Biase, D.; Valentini, I.; Casadei, G.; Paioli, D.; Ferrari, F.; Gordini, G.; Patelli, M.; et al. Randomized Trial of Endobronchial Ultrasound-Guided Transbronchial Needle Aspiration with and without Rapid On-site Evaluation for Lung Cancer Genotyping. Chest 2015, 148, 1430-1437. [CrossRef] [PubMed]

57. Martin-Deleon, R.; Teixido, C.; Lucena, C.M.; Martinez, D.; Fontana, A.; Reyes, R.; García, M.; Viñolas, N.; Vollmer, I.; Sanchez, M. EBUS-TBNA Cytological Samples for Comprehensive Molecular Testing in Non-Small Cell Lung Cancer. Cancers 2021, 13, 2084. [CrossRef]

58. Perrotta, F.; Nankivell, M.; Adizie, J.B.; Maqsood, U.; Elshafi, M.; Jafri, S.; Lerner, A.D.; Woolhouse, I.; Munavvar, M.; Evison, M.; et al. Endobronchial Ultrasound-Guided Transbronchial Needle Aspiration for PD-L1 Testing in Non-small Cell Lung Cancer. Chest 2020, 158, 1230-1239. [CrossRef] [PubMed]

59. Temiz, D.; İn, E.; Kuluöztürk, M.; Kırkıl, G.; Artaş, G.; Turgut, T.; Deveci, F. The role of endobronchial ultrasound-guided transbronchial needle aspiration in the differential diagnosis of isolated mediastinal and/or hilar lymphadenopathy. Diagn. Cytopathol. 2021, 49, 1012-1021. [CrossRef]

60. Grosu, H.B.; Iliesiu, M.; Caraway, N.P.; Medeiros, L.J.; Lei, X.; Jimenez, C.A.; Morice, R.C.; Casal, R.F.; Ost, D.; Eapen, G.A. Endobronchial Ultrasound-Guided Transbronchial Needle Aspiration for the Diagnosis and Subtyping of Lymphoma. Ann. Am. Thorac. Soc. 2015, 12, 1336-1344. [CrossRef]

61. Erer, O.F.; Erol, S.; Anar, C.; Aydoğdu, Z.; Özkan, S.A. Diagnostic yield of EBUS-TBNA for lymphoma and review of the literature. Endosc. Ultrasound 2017, 6, 317-322. [CrossRef]

62. Moonim, M.T.; Breen, R.; Fields, P.A.; Santis, G. Diagnosis and subtyping of de novo and relapsed mediastinal lymphomas by endobronchial ultrasound needle aspiration. Am. J. Respir. Crit. Care. Med. 2013, 188, 1216-1223. [CrossRef]

63. Dayan, G.; Soder, S.; Godin, A.; Maietta, A.; Stephenson, P.; Lemieux, B.; Liberman, M. Endosonography-Guided Biopsy as a First Test in the Diagnosis of Lymphoma. Semin. Thorac. Cardiovasc. Surg. 2021. [CrossRef]

64. Barroca, H.; Marques, C. A Basic Approach to Lymph Node and Flow Cytometry Fine-Needle Cytology. Acta Cytol. 2016, 60, 284-301. [CrossRef] [PubMed]

65. Grosu, H.B. EBUS-TBNA for the Diagnosis of Lymphoma: Time to Give In? J. Bronchol. Interv. Pulmonol. 2018, 25, 165-166. [CrossRef] [PubMed]

66. Trisolini, R.; Baughman, R.P.; Spagnolo, P.; Culver, D.A. Endobronchial ultrasound-guided transbronchial needle aspiration in sarcoidosis: Beyond the diagnostic yield. Respirol. Carlton Vic. 2019, 24, 531-542. [CrossRef]

67. Pedro, C.; Melo, N.; Novais, E.B.H.; Magalhães, A.; Fernandes, G.; Martins, N.; Morais, A.; Caetano Mota, P. Role of Bronchoscopic Techniques in the Diagnosis of Thoracic Sarcoidosis. J. Clin. Med. 2019, 8, 1327. [CrossRef]

68. Goyal, A.; Gupta, D.; Agarwal, R.; Bal, A.; Nijhawan, R.; Aggarwal, A.N. Value of different bronchoscopic sampling techniques in diagnosis of sarcoidosis: A prospective study of 151 patients. J. Bronchol. Interv. Pulmonol. 2014, 21, 220-226. [CrossRef]

69. Dziedzic, D.A.; Peryt, A.; Orlowski, T. The role of EBUS-TBNA and standard bronchoscopic modalities in the diagnosis of sarcoidosis. Clin. Respir. J. 2017, 11, 58-63. [CrossRef]

70. Kasper, L.; Andrychiewicz, A.; Gross-Sondej, I.; Soja, J.; Kasper, M.; Tomaszewska, R.; Urbanczyk, K.; Sladek, K. Combination of endosonography-guided fine-needle aspiration and conventional endoscopic techniques in sarcoidosis diagnosis. Optimal strategy to achieve high diagnostic yield. Clin. Respir. J. 2021, 15, 203-208. [CrossRef] [PubMed] 
71. Kumar, S.; Chandra, S. A “ROSE" in every "EBUS" keeps transbronchial lung biopsy away. Chest 2014, 146, e97. [CrossRef] [PubMed]

72. Oki, M.; Saka, H.; Ando, M.; Nakashima, H.; Shiraki, A.; Murakami, Y.; Kogure, Y.; Kitagawa, C.; Kato, T. How Many Passes Are Needed for Endobronchial Ultrasound-Guided Transbronchial Needle Aspiration for Sarcoidosis? A Prospective Multicenter Study. Respir. Int. Rev. Thorac. Dis. 2018, 95, 251-257. [CrossRef] [PubMed]

73. Sun, J.; Yang, H.; Teng, J.; Zhang, J.; Zhao, H.; Garfield, D.H.; Han, B. Determining factors in diagnosing pulmonary sarcoidosis by endobronchial ultrasound-guided transbronchial needle aspiration. Ann. Thorac. Surg. 2015, 99, 441-445. [CrossRef] [PubMed]

74. Salman, R.; Sutherland, T. Does Endobronchial Ultrasound-guided transbronchial needle aspiration (EBUS) alter the diagnosis in suspected Sarcoidosis? In Proceedings of the ERS International Congress. Madrid, Spain, 28 September-2 October; 2019.

75. Ayub, I.; Mohan, A.; Madan, K.; Hadda, V.; Jain, D.; Khilnani, G.C.; Guleria, R. Identification of specific EBUS sonographic characteristics for predicting benign mediastinal lymph nodes. Clin. Respir. J. 2018, 12, 681-690. [CrossRef]

76. Wang, L.; Wu, W.; Teng, J.; Zhong, R.; Han, B.; Sun, J. Sonographic Features of Endobronchial Ultrasound in Differentiation of Benign Lymph Nodes. Ultrasound Med. Biol. 2016, 42, 2785-2793. [CrossRef] [PubMed]

77. Muthu, V.; Gupta, N.; Dhooria, S.; Sehgal, I.S.; Bal, A.; Aggarwal, A.N.; Behera, D.; Agarwal, R. A Prospective, Randomized, Double-Blind Trial Comparing the Diagnostic Yield of 21- and 22-Gauge Aspiration Needles for Performing Endobronchial Ultrasound-Guided Transbronchial Needle Aspiration in Sarcoidosis. Chest 2016, 149, 1111-1113. [CrossRef]

78. Dhooria, S.; Sehgal, I.S.; Gupta, N.; Bal, A.; Prasad, K.T.; Aggarwal, A.N.; Ram, B.; Agarwal, R. A Randomized Trial Evaluating the Effect of 10 versus 20 Revolutions Inside the Lymph Node on the Diagnostic Yield of EBUS-TBNA in Subjects with Sarcoidosis. Respir. Int. Rev. Thorac. Dis. 2018, 96, 464-471. [CrossRef] 